\title{
A Quantitative Climate-Match Score for Risk-Assessment Screening of Reptile and Amphibian Introductions
}

\author{
Nicola J. van Wilgen · Núria Roura-Pascual · \\ David M. Richardson
}

Received: 3 September 2008 / Accepted: 25 April 2009/Published online: 7 July 2009

(C) Springer Science+Business Media, LLC 2009

\begin{abstract}
Assessing climatic suitability provides a good preliminary estimate of the invasive potential of a species to inform risk assessment. We examined two approaches for bioclimatic modeling for 67 reptile and amphibian species introduced to California and Florida. First, we modeled the worldwide distribution of the biomes found in the introduced range to highlight similar areas worldwide from which invaders might arise. Second, we modeled potentially suitable environments for species based on climatic factors in their native ranges, using three sources of distribution data. Performance of the three datasets and both approaches were compared for each species. Climate match was positively correlated with species establishment success (maximum predicted suitability in the introduced range was more strongly correlated with establishment success than mean suitability). Data assembled from the Global Amphibian Assessment through NatureServe provided the most accurate models for amphibians, while ecoregion data compiled by the World Wide Fund for Nature yielded models which described reptile climatic suitability better than available point-locality data. We present three methods of assigning a climate-match score for use in risk assessment using both the mean and maximum climatic suitabilities. Managers may choose to use different methods depending on the stringency of the assessment and the available data, facilitating higher
\end{abstract}

Electronic supplementary material The online version of this article (doi:10.1007/s00267-009-9311-y) contains supplementary material, which is available to authorized users.

N. J. van Wilgen $(\varangle) \cdot$ N. Roura-Pascual · D. M. Richardson Centre for Invasion Biology (CIB), Department of Botany \& Zoology, Stellenbosch University, P/Bag X1, Matieland,

Stellenbosch, Western Cape 7602, South Africa

e-mail: nvanwilgen@gmail.com resolution and accuracy for herpetofaunal risk assessment. Climate-matching has inherent limitations and other factors pertaining to ecological interactions and life-history traits must also be considered for thorough risk assessment.

Keywords Bioclimatic envelope modeling . Biological invasions · California · Florida .

Generalized additive model - GBIF .

Invasive alien species · Herpetofauna - NatureServe ·

Species distribution modeling $\cdot$ WildFinder

\section{Introduction}

To predict and anticipate the negative consequences of species invasions, managers need appropriate tools. Prevention of high-risk introductions is a crucial component of managing invasions (Kaiser 1999; Mack and others 2000). Consequently, much research effort has been directed at developing tools and protocols for screening and risk assessment of non-native species. Risk assessment provides an objective framework for evaluating the risks associated with the introduction of a species into a new geographic region, by evaluating the likelihood of the species establishing and spreading in an area, and the threat it poses to native ecosystems and human society. This approach has received some criticism, as the ability of theoretical risk models to predict results in the field and their applicability to individual species have been questioned (Williamson 1999). Furthermore, those who stand to benefit from introductions (e.g., through the introduction of economically viable crops or popular pet species) dislike the approach, as the importation of desirable species is delayed or prevented when data required to complete assessments are lacking (Keller and others 2007). However, recent risk 
assessments aimed at specific taxonomic groups have been increasingly successful at predicting potential invaders, e.g., risk assessments for fish (Kolar and Lodge 2002), plants (Daehler and Carino 2000; Pheloung and others 1999), birds (Veltman and others 1996) and reptiles and amphibians (Bomford and others 2009). Though there will always be cases that do not conform to model predictions, the increasing robustness of invasion ecology should help to improve risk predictions (Kolar and Lodge 2001).

Different problems arise when striving for objective risk-assessment protocols in different groups of organisms. Risk assessment for reptiles and amphibians (hereafter herpetofauna) is complicated by an acute lack of data. The life history and basic biology of many species are unknown outside captivity (Reed 2005), and distribution data are poor or nonexistent for the majority of species. Widespread introduction of herpetofauna is recent and in most cases the establishment success/failure rates of non-native populations and adventive distributions are poorly documented (Lever 2003). It is therefore important that we determine how best to use the data that are available.

Risk-assessment models have used a variety of variables to assess invasion potential, including life-history traits, factors limiting reproduction and growth in the introduced range, and various taxon-specific criteria. The degree of climate similarity and invasive history elsewhere have emerged as important predictors of a species invasive potential (Bomford and others 2005; Kolar and Lodge 2001). However, most screening models, while acknowledging the pivotal role of climate-match, use very crude metrics to evaluate it. For example, the technique proposed by Pheloung and others (1999), which has been widely adapted for use on several taxa in many parts of the world (e.g., Gordon and others 2008), simply categorizes climate match as low, intermediate, or high. The same scores categorize the quality of the data used to obtain the climate match. What constitutes low, medium or high climatic suitability is not explained, resulting in subjectivity when used by different people. Increasing accuracy/precision with climate match is therefore desirable, though the purpose of the assessment will dictate the level of precision needed. Furthermore, as data relating to herpetofaunal life-history traits are often lacking, improving the quality of climatematch scores is important, as herpetofaunal risk assessments may rely more heavily on climate data than assessments for other taxa. Recently, Bomford and others (2009) used the program CLIMATE to provide a climate-match score for introduced herpetofauna. The study showed strong correlations between climate and species ability to establish. However, the types of distribution data available for modeling were not explored; and the type of data used to calibrate the models has a potentially dramatic effect on the predictions (Arntzen 2006). Furthermore, the technique used to derive a climate-match score is incorporated in the CLIMATE software and a method to derive a climate match score independent of the program used is still lacking. We thus suggest that exploring the predictive power of different datasets and formulating a consistent method for scoring climatic suitability regardless of the study approach, will improve the application of climate-model predictions.

Several studies have employed bioclimatic envelope models to predict the potential distribution of herpetofauna species (Costa and others 2008; Ficetola and others 2007, 2009; Franklin and others 2009; Guisan and Hofer 2003; Soares and Brito 2007; Teixeira and others 2001). Such models search for non-random correlations among occurrence data and environmental variables influencing a species' distribution, to identify areas worldwide presenting similar environments where species may be able to sustain populations (Guisan and Zimmermann 2000). Here, we apply bioclimatic envelope models to assess global climatic suitability for a number of commonly traded herpetofaunal species. By doing this we aim to (1) assess the potential use and limitations of available distribution data and (2) propose a method of incorporating the resultant climatic suitabilities into scores for use in risk assessment. To achieve these aims, we compare the utility of two different modeling approaches: first we identify areas of the world with equivalent bioclimatic features to the biomes in which species were introduced (herein called "biome approach") to obtain a crude estimate of areas from which invasive species may arise. Secondly, we use a more conventional approach, modeling potential climatic suitability based on the species' native range ("species approach"). Based on the resultant climate suitability predictions, we provide three methods for assigning a climate-match score for risk assessment, taking into account both the risk of the species establishing anywhere in the region and the size of the area potentially affected.

\section{Methods}

Data on herpetofaunal introductions were obtained from Florida and California - two of the regions worldwide with a large number and reasonably long history of introductions (Lever 2003). The majority of these introductions have occurred accidentally along with ship cargo or through the pet trade (Meshaka and others 2004). We have included 53 species introduced to Florida and 17 to California, with three species introduced to both regions, giving a total of 67 species (Collins 1994-2008; Fisher and Case 2003; Florida Fish and Wildlife Conservation Commission 1999-2008; King 1996-2006; Lever 2003; Meshaka and others 2004; Nafis 2000-2008) (see Appendix for species list). We also recorded the status of introduced populations, where this 
information was available, classifying species as: species which failed to establish ("F"); species with persisting populations confined to human adapted areas without spread ("H"); species confined to human adapted areas with population growth ("HS"); species persisting in natural areas, with no spread ("N"); and species which are fully established and spreading ("E") (Lever 2003; Meshaka and others 2004; Nafis 2000-2008).

\section{Bioclimatic Envelope Modeling}

To identify the most appropriate approach for assessing climatic suitability at a global scale in the context of limited data, we examined two different approaches.

\section{Biomes Approach}

This approach is based on a method proposed by Richardson and Thuiller (2007) for plants, which searches for similarity between the biomes present in the introduced range of a species (Florida and California) and the rest of the world. Areas covered by each biome were considered as presence data for the calibration of the models, while areas extralimital to the biome within each state were used as absences. Though this technique was developed for plants, we were interested to test its applicability to herpetofauna. The approach is fairly simple and it could have many applications in risk assessment, especially as it does not rely on species occurrence data. Further details on the biomes approach are given by Richardson and Thuiller (2007).

\section{Species Approach}

This approach followed the more conventional method of using data on species occurrence to model climatic suitability (Guisan and Zimmermann 2000). We used three independent sets of occurrence data and evaluated the performance of each dataset separately. As locality data from the introduced range is scarce, we included only occurrence data from species' native ranges to develop the models. Data from all sources included only presence records and we were forced to use pseudo-absences. These were randomly-generated from areas within the continent where the species is native, thus often using absence points quite far from the species distribution. This decreases the likelihood of using false negatives where species are actually present, but also decreases the discriminatory power between presence and absence. The number of pseudo-absences was equivalent to the number of presence data points available per dataset in the species native range.

For both the biome and species approaches, we used generalized additive models (GAMs) implemented within BIOMOD, an R-based tool (Thuiller 2003). Models were calibrated using a random subset (70\%, "training data") of the occurrence data, and projected on a global scale to identify areas presenting suitable environmental conditions. Model predictions were not extrapolated to regions which had climatic extremes beyond those found in the areas used for model calibration (here the species native distribution range), since differences in the range of environmental conditions between the areas of calibration and projection may truncate the response curves of the variables (Randin and others 2006). The remaining occurrence data (30\%) set aside from the calibration of the model was used to evaluate the accuracy of the model predictions by means of the area under the curve (AUC) of the receiver operator characteristic (Hanley and McNeil 1982) and the Kappa statistic (K) (Cohen 1960). The AUC measure is independent of the threshold at which the model's prediction is considered, and ranges from 0 to 1 ; AUC $=1$ signifies perfect model predictions, while AUC $\leq 0.5$ indicates predictions no better or worse than random. The Kappa statistic requires the use of specific threshold (herein the threshold maximizing the statistic), and ranges between -1 (inverse correlation) and +1 (perfectly correlated); values of $K>0.80$ indicate excellent model predictions, while those between 0.40 and 0.80 are seen as good (Fielding and Bell 1997; Manel and others 2001). All analyses were performed using R v 2.6.2 (R Development CoreTeam 2007) and ArcGIS v 9.2 (ESRI, Redlands, California, USA).

\section{Occurrence Data}

For the biome approach, we used Level I biomes as indicted by the U.S. Environmental Protection Agency as surrogates for occurrence data (USEPA 2007). In total, six biomes were identified (Fig. 1): two in Florida (namely, tropical wet forest and eastern temperate forest) and four in California (marine west coast forest, north-western forested mountains, North American deserts, and Mediterranean California). The biome polygons were rasterized at the same resolution as the climatic data set $\left(10^{\prime} \times 10^{\prime}\right)$, which corresponded to approximately $17 \mathrm{~km} \times 18 \mathrm{~km}$ cells in Florida and $14 \mathrm{~km} \times 18 \mathrm{~km}$ cells in California.

For the species approach, we used data from three different sources: (1) locality data (latitude/longitude coordinates) from museum collections accessed through the Global Biodiversity Information Facility (GBIF), which was available for 36 of the 67 species included in the study (GBIF 2008); (2) Ecoregion polygon maps from WildFinder, available for 66 species (WWF 2006); and (3) polygon maps of species distribution from NatureServe, available for 11 of the 12 amphibian species (IUCN, Conservation International, and NatureServe 2006). Each data type has associated advantages and shortfalls. Though locality data are the most appropriate for model calibration, 


\section{California and Florida biome predictions}

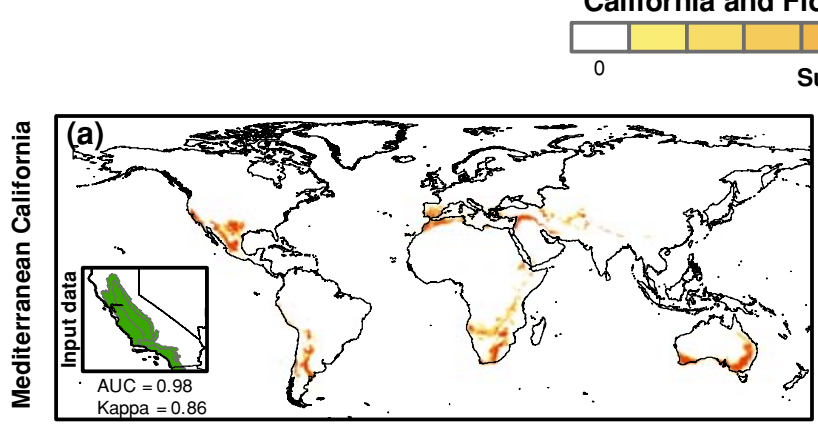

Suitabillity
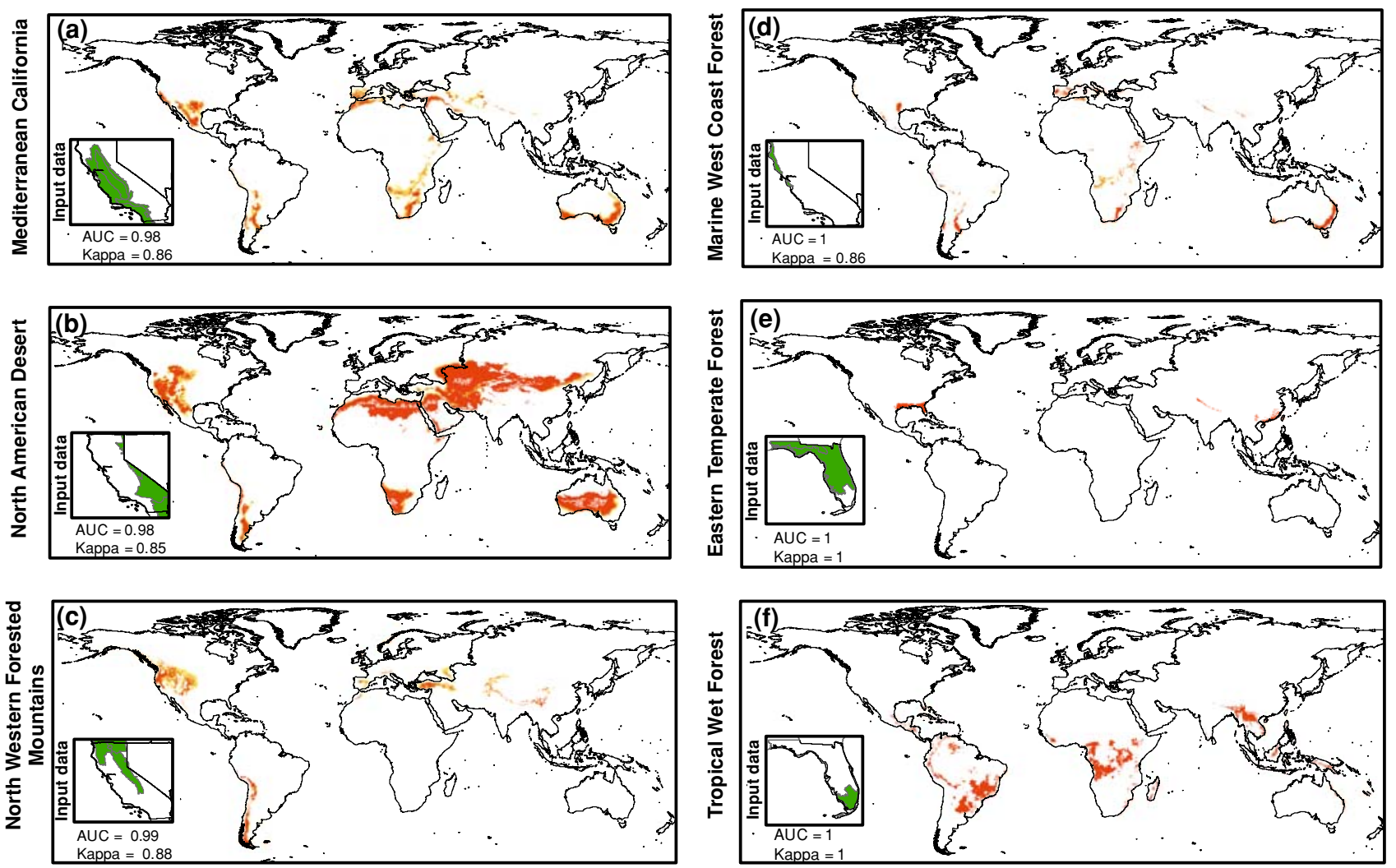

Fig. 1 The global distribution of areas with climates similar to California and Florida: a Mediterranean California, b North American deserts, c north-western forested mountains, $\mathbf{d}$ marine west coast forest, e eastern temperate forest and $\mathbf{f}$ tropical wet forest [areas in

white have a probability of 0 , while probabilities from 0.1 to 1 are represented by a gradient from yellow to red (1)]. High-resolution maps are available as supplementary material online

the GBIF data include localities from only a portion of the species range and might thus underestimate species' distributions. WildFinder recognizes 827 ecoregions worldwide on the basis of climatic conditions as well as floral and faunal distributions. Presence/absence of species is extrapolated at the ecoregion level, with species being marked as present or absent from an entire ecoregion. Species presence can thus be recorded over a larger area than their true occupancy, which may result in overestimated distributions when modeled. NatureServe polygon data was only available for amphibians. However, extrapolations done for these data have been performed separately for each species as opposed to extrapolations at ecoregion level. All polygon data were rasterized to match the resolution of the climate data set $\left(10^{\prime} \times 10^{\prime}\right)$.

\section{Environmental Data}

For climatic data, we used the CRU CL 2.0 global dataset at $10^{\prime} \times 10^{\prime}$ spatial resolution (New and others 2002). Following Richardson and Thuiller (2007), the variables

used for the biomes approach were: (1) annual temperature sum above $5^{\circ} \mathrm{C}$ (AT5), (2) minimum temperature of the coldest month (MinTC), (3) humidity index (mean ratio of annual actual over annual potential evapotranspiration) (HI), and (4) plant productivity index (PPI) ["the number of months per year receiving more rainfall than twice the mean annual temperature for that site that provides a surrogate for the rainfall seasonality and the length of the growing season" (Richardson and Thuiller 2007)].

The variables used in the biomes approach were originally conceived for predicting climatic suitability for plants and differ from those generally used to delineate the distribution of herpetofauna. Temperature and precipitation, as well as altitude, have been particularly important in explaining herpetofaunal distributions (Costa and others 2008; Guisan and Hofer 2003; Soares and Brito 2007). Consequently, for the species approach we chose six variables: three variables described precipitation and its seasonality (mean annual precipitation, wet days per year and coefficient of variation of precipitation), two defined temperature tolerances in the native range (mean minimum temperature of the coldest 
month and mean maximum temperature of the hottest month), and one indicated elevation.

\section{Analysis of Model Results}

Though we made global predictions, we wished to determine the role of climate in species establishment and the effect of different data on model results. Therefore, we were interested in the extent of suitable climate in the introduced range of species, as well as the extent of overlap between the biomes in the introduced range and the species native ranges. For the biomes approach, the climatic suitability predicted by the models was recorded in each cell in the species native range. The mean and maximum of these predictions were calculated per species separately for each distribution dataset (Wilfinder, Naturserver and GBIF). Similar methodology was followed for the species approach. However, as the exact location of introduction and establishment of species was not always available, we extracted mean and maximum climatic suitability predictions at the level of county of introduction/establishment as well as at state level (Florida or California), as would typically be done when performing a risk assessment study. This was done separately for each dataset.

The next step was to determine how well models built from each dataset predicted areas of species establishment, as well as the effect of scale (county versus state). For this we used Spearman's rank order correlations. Species were ranked in one of five categories on the basis of their establishment success (as denoted in the first paragraph of methods): $\mathrm{F}=0, \mathrm{H}=0.25, \mathrm{HS}=0.5, \mathrm{~N}=0.75$ and $\mathrm{E}=1$. These ranks were then compared to the mean and maximum climatic-suitability predictions obtained in both states and counties of introduction. Cells in the state or county of introduction are used here as a surrogate for species presences (for successful species) or absences (for failed species) in the introduced range. The process was replicated using two different binary combinations of establishment success: (1) one combination for established species (Binary E), where all species were ranked 0 except species which had fully established $(\mathrm{E})$ that were ranked 1; and (2) another combination for naturalized species (Binary $\mathrm{N}$ ), where species in categories $\mathrm{F}, \mathrm{H}$ and $\mathrm{HS}$ were ranked 0 and species in categories $\mathrm{N}$ and $\mathrm{E}$ were ranked 1. The Binary $\mathrm{N}$ grouping was used as species in category "N" (naturalized in natural areas) demonstrate the ability to survive and reproduce in local climatic conditions and are therefore not restricted by climate. Rank order correlations were compared between datasets as well as between state and county levels. As there were only seven species for which all three datasets were available, only these were included for comparative purposes. However, we repeated the analysis using only GBIF and WildFinder distribution data, thus providing a larger comparative sample size $(n=33)$.

\section{Climate-Match Score}

For model results such as those produced here to be useful for informing risk assessment, the results need to be translated into some simple form of scoring system. Here we propose three options for assigning a climate-match score across the introduced range of each species. Firstly, we define a continuous variable for climate-match, which can be converted to a categorical score, should such a score be required. We can therefore make informed decisions about the criteria used for defining score categories, making the classification process more transparent.

Score $\mathrm{M}$ accounts for divergences between the mean and maximum predicted values: where all predictions are similar, the score approximates the mean. Score $\mathrm{M}$ is computed by weighting the maximum prediction as follows:

Biomes approach $\mathrm{M}=($ mean prediction + maximum

prediction across native range) $/ 2$

Species approach $\mathrm{M}=($ mean prediction + maximum

prediction across introduced range) $/ 2$.

We used this method to account for cases where the average predicted suitability was very low (approaching 0), but where there were a few cells with high suitability (near 1). In such cases the maximum predicted estimate was an outlier, falling outside the $95 \%$ confidence intervals. Yet, at the coarse scale of this study, a prediction of high suitability in a single grid cell $\left(300-\mathrm{km}^{2}\right)$ must be flagged as important. We therefore reasoned that weighting the maximum estimate was appropriate.

Score $\mathrm{C}$ places species into one of 10 categories on the basis of the mean and maximum predicted values in the region of interest. These categories are defined by a 10celled table (detailed in Fig. 2) and attempt to reflect an increase in climatic suitability with an increase in score $\mathrm{C}$. To reduce the subjectivity in the score assignment, we validated the scores using the introductions to Florida as a test case. Species were categorized according to their establishment success (F, H, HS, N and E) and placed into the celled table detailed in Fig. 2, on the basis of their predicted mean and maximum climatic suitabilities in Florida. Thus cells can be classified based on the establishment outcome of the majority of species in the cell: F, $\mathrm{H}, \mathrm{HS}, \mathrm{N}$ and $\mathrm{E}$. However, the data detailing the fate of introduced populations was not good enough to enable classification of all cells. Consequently, we present two scores: a numerical score (C Num), which can be defined a priori on the basis of predicted climatic suitability; and a categorical score (C Cat) which uses species introduction 


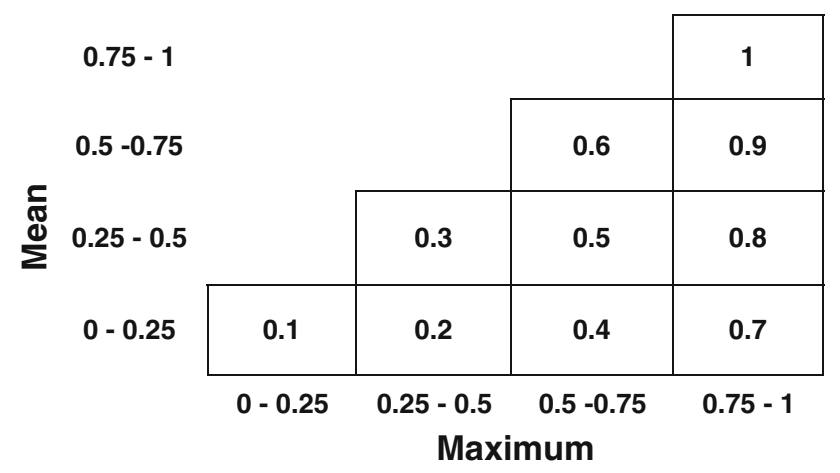

Fig. 2 Climate-match score $\mathrm{C}$ is represented by a categorical variable between 0 and 1 based on the value of the mean and the maximum predicted climatic suitability across a region

success a posteriori to assign establishment categories to cells in the table for use in future risk assessments.

Score $\mathrm{T}$ is based on thresholds. The threshold at which climate is deemed suitable for a species is often arbitrarily decided, and the use of different methods introduces subjectivity (see Woolf and others 2002 for an example). However, by plotting the percentage of cells above a series of predicted suitability thresholds, the effect of choosing different thresholds can be seen. This was done for all species, for ten thresholds ranging from 0.1 to 1 . The score assigned at each threshold is thus the percentage of cells predicted to have a suitability at or above that threshold in a given area (in our case, the state or county of introduction of the species). The climate-match score $\mathrm{T}$ can be calculated as the sum of the scores at thresholds 0.1 through 1 divided by 1,000 , to give a value between 0 and 1 . In many cases this value approximates the mean climatic suitability. There are ten variations on this score if the above increments are used: the first is the score at threshold 0.1 (score $\mathrm{T} 1)$; the second is the sum of the scores at the first $(0.1)$ and second threshold (0.2) (score T2) and so on until all ten threshold scores are summed (score T10). Having the area covered by each threshold of climatic suitability allows one to analyze the effect of setting different threshold suitabilities on the outcome of a risk assessment. Depending on the purpose of the assessment, cumulative thresholds can be calculated to include more or less stringent criteria as was done by Bomford and others (2009). One may also chose not to use summed thresholds where lower predictions are deemed unimportant.

\section{Results}

\section{Bioclimatic Envelope Modeling}

In total, 136 models were run for the six biomes (6) and the 67 species (130). The AUC's of models calibrated using the biome and species approaches were high (mean AUC $=0.97$, $\min =0.82$ ), showing that the models correctly predicted biome/species occurrence in the native range. Kappa values also indicated good model fit (mean $\mathrm{K}=0.89, \min \mathrm{K}=0.59$ ) (Appendix).

For the biomes approach, the North American Desert biome in California had the broadest predicted worldwide distribution, while the remaining five biomes from California and Florida were predicted to cover much smaller areas (Fig. 1). The mean climatic suitability predicted in species native ranges by the six biomes was 0.08 , while the maximum prediction averaged across species was 0.76 (Table 1). This compares to 0.41 and 0.81 respectively when using the species approach (Table 1). Consequently, the biomes approach led to consistently lower climate match scores than the species approach.

For the species approach, models produced for species with small distribution ranges, generated constantly high suitability predictions (e.g. Anolis cybotes), while species with larger ranges were predicted to have more variable predicted values worldwide. Species with the broadest worldwide climatic suitability included the boa constrictor (Boa constrictor), three geckos of the Hemidactylus genus, the iguana Ctenosaura pectinata, and amphibians Lithobates berlandieri and Chaunus marinus, though these predictions were not consistent across datasets (results for all species are summarized in the Appendix, and maps of predicted climatic suitability are available for all 67 species as part of the supplementary material).

Lithobates catesbeianus (the American bullfrog, formerly Rana catesbeiana, see Frost and others 2006) is one of the best-studied invasive amphibian species (e.g., Ficetola and others 2007; Kupferberg 1997). We present the model results of this species as a case study (Fig. 3). The species is native to Canada, southern and eastern USA and Mexico, but has expanded its range to cover much of North America, including large parts of California (IUCN 2006). Models for all three species occurrence datasets produced mean suitability predictions between 0.43 and 0.73 across California, with maximum predictions near 1 (100\% suitability) for all models (Fig. 3). The biomes approach produced consistently lower suitability predictions (mean climatic similarity predicted by Californian biomes $=0.06$ ). This difference appears to be even more pronounced in areas outside of America where L. catesbeianus has been introduced (compared visually).

Model prediction and performance (as measured by AUC and Kappa) tell us nothing about how well the models predicted in the introduced range, and consequently, we used rank-order correlations to determine which models were best in predicting species occurrence in the introduced range for the species approach. Predicted suitabilities for the biomes approach were so low that we 
Table 1 Summary of the climatic suitabilities for herpetofauna introduced to Florida and California, calculated using the biomes and species approaches

\section{Maximum}

Mean

0.78

1.00

Average

Biomes (mean across all biomes)

$\begin{array}{ll}\text { Average } & 0.76 \\ \text { Max } & 1.00\end{array}$

\section{ETF}

$\begin{array}{ll}\text { Average } & 0.33 \\ \text { Max } & 1.00 \\ \text { THF } & \end{array}$

$\begin{array}{ll}\text { Average } & 0.9 \\ \text { Max } & 1.00 \\ \text { MC } & \end{array}$

$\begin{array}{ll}\text { Average } & 0.93 \\ \text { Max } & 1.00 \\ \text { MWCF } & \end{array}$

$\begin{array}{cc}\text { Average } & 0.88 \\ \text { Max } & 1.00 \\ \text { NAD } & \\ \text { Average } & 0.82 \\ \text { Max } & 1.00 \\ \text { NWFM } & \end{array}$

$\begin{array}{ll}\text { Average } & 0.65 \\ \text { Max } & 1.00\end{array}$

Species (mean across all datasets)

$\begin{array}{ll}\text { Average } & 0.81 \\ \text { Max } & 1.00 \\ \text { GBIF } & \end{array}$

\begin{tabular}{|c|c|c|c|c|c|}
\hline Average & 0.74 & 0.37 & 163.61 & 0.55 & 0.64 \\
\hline Max & 1.00 & 1.00 & 2017.28 & 1.00 & 1.00 \\
\hline \multicolumn{6}{|l|}{ WildFinder } \\
\hline Average & 0.96 & 0.61 & 97.50 & 0.78 & 0.89 \\
\hline Max & 1.00 & 1.00 & 2172.56 & 1.00 & 1.00 \\
\hline \multicolumn{6}{|l|}{ NatureServe } \\
\hline Average & 0.74 & 0.26 & 176.70 & 0.50 & 0.60 \\
\hline Max & 1.00 & 0.78 & 636.16 & 0.88 & 1.00 \\
\hline
\end{tabular}

We present the mean and maximum predicted suitability values, as well as Score M and Score C Num (see methods for their description), averaged across biomes (MC Mediterranean California, NAD North American deserts, NWFM north-western forested mountains, $M W C F$ marine west coast forest, ETF eastern temperate forest, $T H F$ tropical wet forest) and species for each distribution dataset (GBIF WildFinder or NatureServe). The highest (maximum) mean and maximum prediction obtained by any species in a given set of models is also recorded

did not attempt such correlations for this approach. Using the species approach, we found climatic suitability to be positively correlated with species establishment success for all models. Though models developed using the WildFinder data produced the highest predictions (Table 1), models derived from the NatureServe dataset were more strongly correlated to species establishment success (state level: $r=0.88$, county level: $r=0.75)$, despite predicting lower overall climatic suitability (though the sample size was small $(n=7)$, Table 2$)$. The maximum predicted suitability was more strongly correlated to species establishment than the mean suitability, where these differed, in all but one comparison (NatureServe when comparing predictions at county level) (Table 2). Furthermore, using a 
Fig. 3 The probability of occurrence of the American bullfrog (Lithobates catesbeianus) at a global scale calibrated using occurrence data from three sources: WildFinder, GBIF and NatureServer. The maps on the left represent the predicted climatic suitability, while the maps on the right show the data which were used as model inputs. The model performance and the mean and maximum predicted climatic suitability in the bullfrog's introduced range (California) are given per model in the table alongside each map at both state and county level. Highresolution color maps are available as supplementary material online

\section{Lithobates catesbeianus}
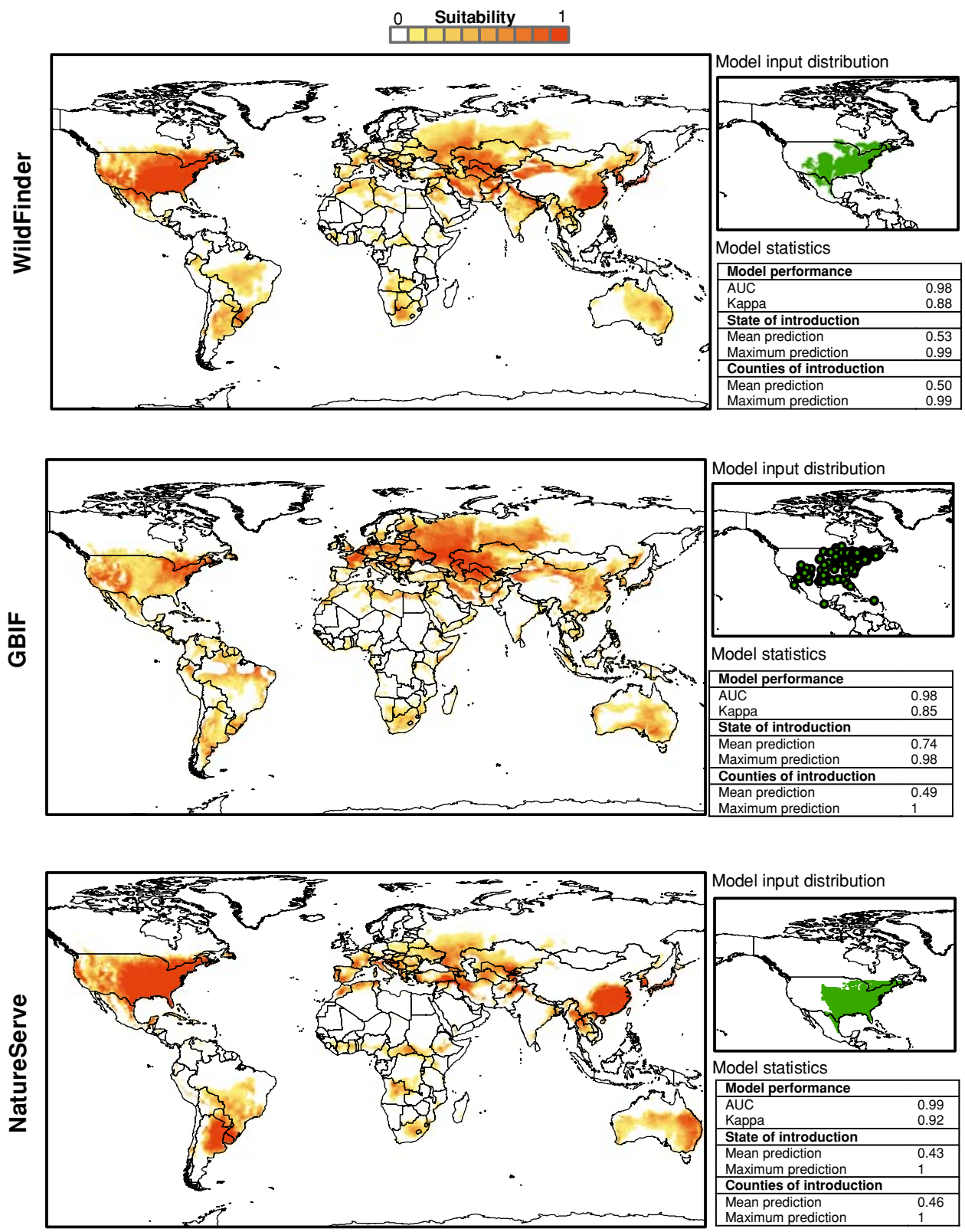

binary category distinction was as good or better at predicting species presence than using five categories of establishment in most comparisons. More interestingly, Binary $\mathrm{E}$ which classified naturalized, but non-spreading species as failed introductions performed better than Binary $\mathrm{N}$ (where these species were considered established) when correlated to mean scores, but worse when correlated to maximum scores. There was no clear pattern with regard to the best discrimination of establishment success according to scale (Table 2). The WildFinder dataset performed better than GBIF at both state and county levels using mean and maximum suitabilities (Table 2).
Climate-Match Scores

Score M (where the maximum predicted suitability was weighted relative to average predictions) was consistently lower than Score C Num, where species were placed in categories as detailed in Fig. 2 (Table 1). Finding support for Score C Cat categories was not possible due to insufficient data (Fig. 4): species belonging to intermediate categories of establishment [e.g. naturalized $(\mathrm{N})$ ] did not group to any specific cells, though species in cells 0,1 and 2 , where mean and maximum predicted suitability was low, tended to be those with low observed establishment success 
Table 2 Results of Spearman's rank order correlations comparing models calibrated using different sets of species occurrence data, at both the scale of the state and counties of introduction

\begin{tabular}{|c|c|c|c|c|c|c|c|}
\hline \multirow[t]{2}{*}{ Dataset } & \multirow[t]{2}{*}{ Scale } & \multicolumn{3}{|c|}{ Mean climatic suitability } & \multicolumn{3}{|c|}{ Maximum climatic suitability } \\
\hline & & Categorical & Binary $\mathrm{E}$ & Binary $\mathrm{N}$ & Categorical & Binary E & Binary $\mathrm{N}$ \\
\hline \multicolumn{8}{|c|}{ (a) All datasets $(n=7)$} \\
\hline \multirow[t]{2}{*}{ GBIF } & State & 0.38 & 0.38 & - & 0.38 & 0.38 & - \\
\hline & County & 0.50 & 0.50 & - & 0.50 & 0.50 & - \\
\hline \multirow[t]{2}{*}{ WildFinder } & State & 0.63 & 0.63 & - & 0.88 & 0.88 & - \\
\hline & County & 0.63 & 0.63 & - & 0.75 & 0.75 & - \\
\hline \multirow[t]{2}{*}{ NatureServe } & State & 0.88 & 0.88 & - & 0.88 & 0.88 & - \\
\hline & County & 0.88 & 0.88 & - & 0.75 & 0.75 & - \\
\hline \multicolumn{8}{|c|}{ (b) GBIF and WildFinder $(n=33)$} \\
\hline \multirow[t]{2}{*}{ GBIF } & State & 0.11 & 0.23 & 0.17 & 0.19 & 0.23 & 0.27 \\
\hline & County & 0.09 & 0.20 & 0.16 & 0.20 & 0.25 & 0.26 \\
\hline \multirow[t]{2}{*}{ WF } & State & 0.36 & 0.39 & 0.31 & 0.40 & 0.39 & 0.45 \\
\hline & County & 0.27 & 0.33 & 0.27 & 0.53 & 0.59 & 0.37 \\
\hline
\end{tabular}

(a) Compares results from all three datasets (GBIF WildFinder and NatureServe) using the mean and maximum climatic suitability predictions respectively $(n=7)$, while (b) compares results of the GBIF and WildFinder datasets only $(n=33)$. The columns of data represent three different rankings of species establishment success (see "Methods")

(Fig. 4). The majority of species in cells 7 to 10 , where the maximum predicted suitability was high, had high establishment success [61\% fully established, 94\% some degree of establishment, excluding species for which no data was available (Fig. 4)]. Ameiva ameiva, Hemidactylus mabouia and Tupinambis merianae had the highest mean predicted suitability in Florida; where all three species are now established (W.E. Meshaka pers. comm.), affording support for our scoring system where the maximum values are weighted. Some species however did have high predicted climatic suitability but have not established in Florida outside human dominated ecosystems (e.g., Anolis garmani and Hemidactylus frenatus).

Graphs of score $\mathrm{T}$ provided the clearest way of visualizing the extent of the climatic suitability. These plots showed that for a majority of species, higher suitability was observed in the counties of introduction than across the entire state (see Fig. 5). The yellow-headed gecko (Gonatodes albogularis) specifically demonstrates the effect that different scales will have on a risk assessment (state level: $\mathrm{T} 5=0.11, \mathrm{~T} 9=0.07$ and county level: $\mathrm{T} 5=0.92$, T9 $=0.61)$ (Fig. 5). The threshold of climatic suitability set for such an assessment will also affect the outcome, though this will be more marked for species where climatic suitability is predicted to be variable (e.g. the brown anole (Anolis sagrei), T5 $=0.53, \mathrm{~T} 9=0.39, \mathrm{~T} 10=0.35$, or the cane toad (Chaunus marinus) T5 $=0.99, \quad \mathrm{~T} 9=0.64$, $\mathrm{T} 10=0.58)$ than for species where predictions are consistently high or low (e.g. Burmese python (Python molurus), T5 $=1$, T9 $=0.99$ or the common agama (Agama agama), $\mathrm{T} 5=\mathrm{T} 9=0.20)($ Fig. 5$)$.

\section{Discussion}

Predicting species' distribution at a global scale relies on accurate distribution data to parameterize models. Given the dearth of distribution data for most herpetofauna for use in screening introductions, we set out to use a method which did not rely on accurate distribution data (the biomes approach). This approach was, however, less successful than we would have hoped. Small biomes are problematic for making predictions at such a large scale, especially as predictions made beyond extremes encountered in the area of model calibration were excluded (Randin and others 2006). We also compared the predictive capabilities of three types of species distribution data for 67 herpetofaunal species and suggest how these predictions could be used to calculate a climate-match score for use in risk assessment.

\section{Performance of Species Distribution Data}

The WildFinder dataset predicted larger suitable areas than data from NatureServe and GBIF, and thus provides the most conservative estimates for risk assessment. These data are available for many species and taxa, making WildFinder a useful source for future studies. However, as these data overestimate many species' distributions, results should be interpreted with caution. Problems may arise where beneficial species are flagged as potential invaders on the basis of a strong climate match, where in fact this has been overestimated. Though this dataset performed relatively well when compared to GBIF (Table 2), its poorer performance compared to NatureServe can be 
Fig. 4 The role of climate in predicting establishment success of species introduced to Florida. Success of species is indicated by the colors depicted in the legend (see online version for color). Where success is uncertain, a combination of colors depicting the most likely outcomes has been used. Species are placed in cells based on the mean and maximum climatic suitability in Florida predicted by each dataset (WildFinder, GBIF and NatureServe). Categories describing the relative invasive potential of species in each cell can be assigned based on the success of species in the cell

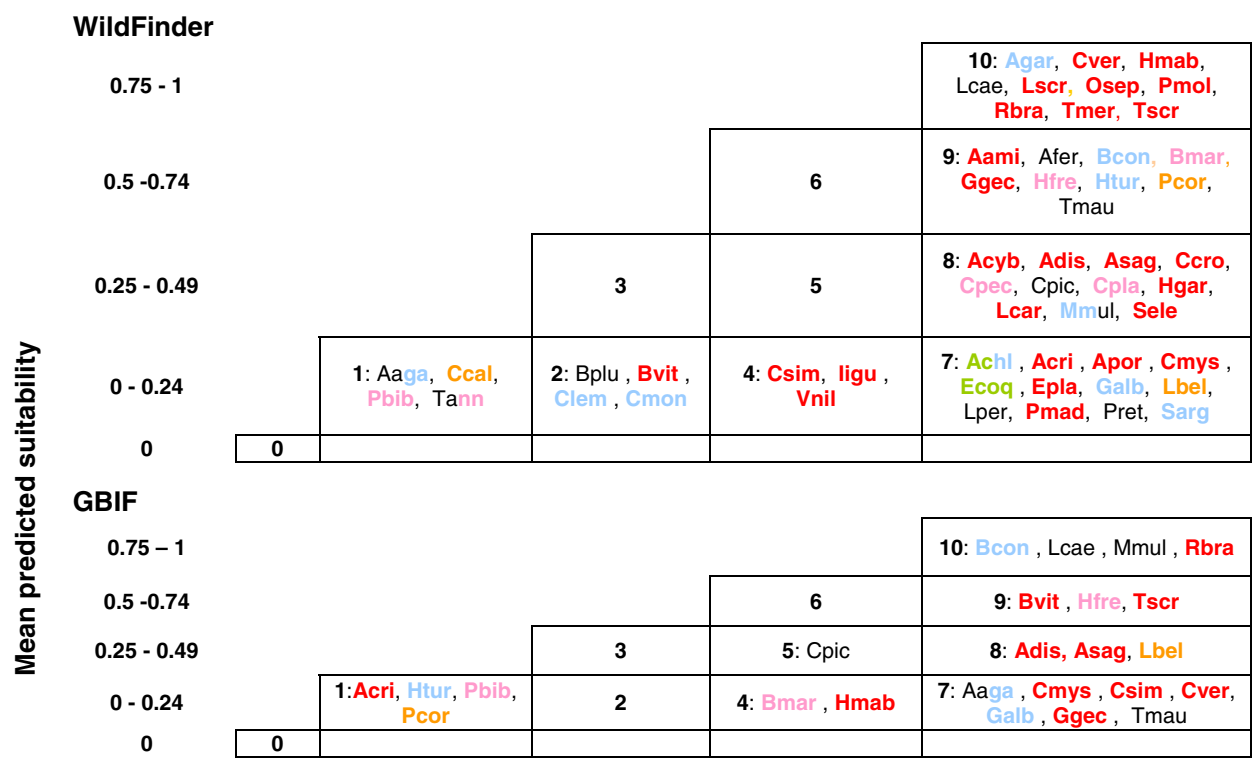

NatureServe

\begin{tabular}{|c|c|c|c|c|c|}
\hline \multicolumn{3}{|l|}{$0.75-1$} & & & 10: Lcae \\
\hline \multirow{2}{*}{\multicolumn{3}{|c|}{$\begin{array}{c}0.5-0.74 \\
0.25-0.49\end{array}$}} & & 6 & 9 \\
\hline & & & 3 & 5 & 8 \\
\hline \multicolumn{2}{|l|}{$0-0.24$} & 1: Ecoq, Bmar & 2 & 4 & 7: Epla, Osep \\
\hline \multirow[t]{2}{*}{0} & 0 & & & & \\
\hline & 0 & $0-0.24$ & $5-c$ & $5-0$. & $0.75-1$ \\
\hline
\end{tabular}

\begin{tabular}{|c|c|c|c|c|c|}
\hline Established (E) & $\begin{array}{c}\text { Naturalized } \\
\text { outside urban } \\
\text { areas, no spread } \\
\text { (N) }\end{array}$ & $\begin{array}{l}\text { Established in } \\
\text { urban areas with } \\
\text { spread / Possibly } \\
\text { established (HS) }\end{array}$ & $\begin{array}{l}\text { Restricted to } \\
\text { urban areas with } \\
\text { no spread }(H)\end{array}$ & Failed (F) & $\begin{array}{l}\text { Not enough data } \\
\text { to categorize }\end{array}$ \\
\hline
\end{tabular}

Species codes
\begin{tabular}{|l|l|l|l|l|l|}
\hline Aaga & Agama agama & Cmys & Calotes mystaceus & Lper & Leiocephalus personatus \\
\hline Aami & Ameiva ameiva & Cpec & Ctenosaura pectinata & Lscr & Leiocephalus schreibersii \\
\hline Achl & Anolis chlorocyanus & Cpic & Chrysemys picta & Mmul & Mabuya multifasciata \\
\hline Acri & Anolis cristatellus & Cpla & Cosymbotus platyurus & Osep & Osteopilus septentrionalis \\
\hline Acyb & Anolis cybotes & Csim & Ctenosaura similis & Pbib & Pachydactylus bibroni \\
\hline Adis & Anolis distichus & Cver & Calotes versicolor & Pcor & Phrynosoma cornutum \\
\hline Afer & Anolis ferreus & Ecoq & Eleutherodactylus coqui & Pmad & $\begin{array}{l}\text { Phelsuma } \\
\text { madagascariensis }\end{array}$ \\
\hline Agar & Anolis garmani & Epla & $\begin{array}{l}\text { Eleutherodactylus } \\
\text { planirostris }\end{array}$ & Pmol & Python molurus \\
\hline Apor & Anolis porcatus & Gall & Gonatodes albogularis & Pret & Python reticulatus \\
\hline Asag & Anolis sagrei & Ggec & Gekko gecko & Rbra & Ramphotyphlops braminus \\
\hline Bcon & Boa constrictor & Hfre & Hemidactylus frenatus & Sarg & Sphaerodactylus argus \\
\hline Bmar & Chaunus marinus & Hgar & Hemidactylus garnotii & Sele & Sphaerodactylus elegans \\
\hline Bplu & Basiliscus plumifrons & Hmab & Hemidactylus mabouia & Tann & Tarentola annularis \\
\hline Bvit & Basiliscus vittatus & Htur & Hemidactylus turcicus & Tmau & Tarentola mauritanica \\
\hline Ccal & Chamaeleo calyptratus & ligu & Iguana iguana & Tscr & Trachemys scripta \\
\hline Ccro & Caiman crocodilus & Lbel & Leiolepis belliana & Tmer & Tupinambis merianae \\
\hline Clem & Cnemidophorus lemniscatus & Lcae & Litoria caerulea & Vnil & Varanus niloticus \\
\hline Cmon & Cnemidophorus montaguae & Lcar & Leiocephalus carinatus & & \\
\hline
\end{tabular}

explained by the number of cases where higher predictions were made for species which had failed to establish.

Most other attempts to model herpetofaunal distributions have used point-locality data obtained from surveys or atlases for localized studies (e.g., Arntzen 2006; Soares and Brito 2007; Franklin and others 2009) or GBIF data for studies at a larger scale (e.g., Costa and others 2008;
Giovanelli and others 2007). Recently GBIF has also included a "niche model" tool on their website, allowing users to select from a number of environmental variables to model species potential distributions using OpenModeller (Sutton and others 2007). The environmental data used is obtained from WorldClim (Hijmans and others 2005), which provides much higher resolution than in our study. 


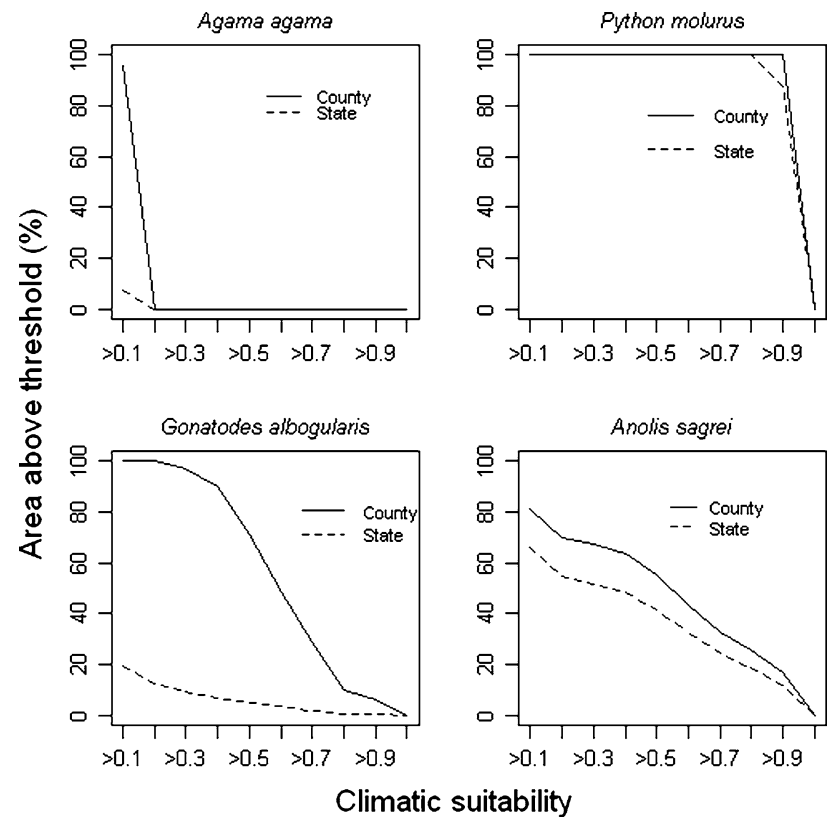

Fig. 5 Examples showing the area (in \%) predicted as climatically suitable across ten thresholds for four species at both state and county scales. Where predictions are consistently high or low, changing the threshold for use in a risk assessment has little effect, as can be seen from the Burmese python (Python molurus; Pythonidae) and the common agama (Agama agama; Agamidae); these examples represent a successful and an unsuccessful introduction. For species where climatic suitability is predicted to be variable [e.g., the brown anole Anolis sagrei (Polychrotidae)], changing the desired threshold suitability will have a more dramatic effect; while species like the yellow-headed gecko (Gonatodes albogularis; Gekkonidae), demonstrate that the scale at which an assessment is done is also important. Solid lines indicate results at the scale of the county of introduction, and dashed lines represent the state scale; models presented used WildFinder data

This application may be useful for managers wanting a first look at the potential ranges of species and the variables which limit these and we look forward to future developments. However, this application, as well as the data provided by GBIF, need to be used with caution. Such data do not necessarily capture the boundaries of the species' distributions and therefore do not fully describe the environmental changes which occur at the species distribution edge (Arntzen 2006). This has implications for building models. Indeed, models developed using only range boundaries and factors linked to species absences have proved to be very useful in identifying areas suitable for the Burmese python (Rodda and others 2009), though this particular model has received criticism (Pyron and others 2008). An additional constraint of the GBIF data is that there is no record of whether or not localities fall within the native range of a species. Non-applicable outliers may therefore be included (e.g., escaped pets or research specimens may be collected and included in museum records).
We therefore recommend that these data should be used with caution, or in combination with other data.

The NatureServe distribution data are the product of intensive studies and expert consultation during the Global Amphibian Assessment (http://www.natureserve.org/projects/ latin_america.jsp\#global). Though the maps produced still approximate species' distributions, these data have been cross-checked at the species level. Indeed, though we only had a small comparative sample, these data produced models which most accurately described species establishment success. However, the data included here were based on current distributions, which are substantially reduced in some cases following amphibian decline (Blaustein and Kiesecker 2002), and data on extirpated populations were not always available. This is not ideal for bioclimatic envelope modeling as the full extent of the potential range of species is not described. This could explain the narrower predictions obtained using these data. Nonetheless, these data are probably the best source (of those analyzed) for future modeling attempts, as they are reliable and available for all amphibian species. It is unfortunate that data at this resolution are not currently available for reptiles.

\section{Assigning Climate-Match Scores}

The assignment of climate-match scores requires careful consideration. The difficulty in assigning a climate-match score arises from the degree of subjectivity introduced in score calculation. As risk assessments are often carried out over large areas (e.g. risk is often assessed for a whole country; van Wilgen and others 2008), it is important to consider the value of average versus maximum estimates of climatic suitability. Some species had small areas predicted as highly suitable, but low average suitability (e.g. Anolis cristatellus and Phelsuma madagascariensis). In such cases, if the mean was used to assign a score, one would predict that the species would fail to establish, while the area with high suitability may indicate a node where establishment could occur (indeed maximum suitability showed better correlation to establishment success than mean suitability). The impact that a species will have should it establish may also determine the stringency of decision criteria needed, as will the purpose of the assessment.

By using a weighted maximum value relative to the mean, one incorporates a measure of the mean and variation, making score $\mathrm{M}$ useful for comparing and prioritizing species. Accordingly, species with consistently high predictions will rank above those where some predictions were high, but the mean prediction is low (see Score M). In an attempt to derive a categorical score from this continuous variable in a more transparent way, we generated score "C Cat" (a categorical variable which uses climatic 
suitabilities of previously introduced species to assign success categories). Unfortunately, we did not have enough information to categorize the range of climate-match scores which delineate all phases of establishment success and thus the description of some categories remains subjective. However, this may not be the case for all taxonomic groups and the method may be considered for use on other taxa, by examining establishment success a posteriori and assigning formal categories to each climatic suitability prediction. Finally, to get an idea of the range of climatic suitabilities, we looked at the percentage of predictions above a series of thresholds. This not only gives an idea of the range of predicted suitability values, but also provides insight into the effect that the scale of an assessment may have (Fig. 5). We do not advocate choosing a single threshold a priori, as the variability in plots produced by the 67 species indicates that much data may be lost in this way. Plotting the climate match at different thresholds will reveal the detail in the data; and by using cumulative thresholds and comparing the effect of different levels of accumulation (e.g., T5 vs. T7), managers may objectively evaluate species on an individual basis, enabling higher resolution and accuracy for risk assessment in this group.

Incorporating the phase of species invasion would also be useful: species may appear to be confined to human dominated ecosystems, or have low invasion rates, simply because of the short residence time in the region or due to there being insufficient "propagules" to establish a viable population (Mack and others 2000). Failure of a species to establish and/or spread when it was predicted to do so or vice versa could be the result of any, or a combination of, factor(s) other than climate in the introduced range (see discussion in Wilson and others 2007). Managers need to be aware that failed introductions cannot be interpreted with much meaning in the context of climate matchingthe inclusion of false negatives can lead to false conclusions, where other factors were the main contributors. For example, Hemidactylus garnotti, and to a lesser extent $H$. frenatus, have been "marginalized" and out-competed in many areas in Florida by another invader, H. mabouia (Meshaka and others 2006). It appears that two Hemidactylus species are not able to co-exist stably and that $H$. mabouia is out-competing other members of this genus regardless of the climatic suitability of the area (Meshaka and others 2004, 2005). This may explain a portion of the variability seen in the correlation between climatic suitability and establishment success. In addition, life-history traits of species and biotic interactions in the area of introduction will influence the degree to which climatic factors are important (Ficetola and others 2007; Pitt and others 2005). Thus it is important that results from studies such as this one form only part of an overall risk analysis (Stohlgren and Schnase 2006).

\section{Model Uncertainties and Future Directions}

There are many uncertainties related to bioclimatic envelope modeling, which result from errors and assumptions in the models themselves as well as poor understanding of how some of the processes related to species interactions work (Heikkinen and others 2006). We discuss these in some detail here not to detract from our study, but to highlight some of the areas that may be particularly pertinent to herpetofaunal risk assessment.

Firstly, there are problems associated with the data. Our models were based on presence-only data from the native range. Where reliable absence data are available, models built using species presences as well as absences are more powerful than those used here (Ferrier and others 2002). These data are unfortunately not available for sufficient numbers of herpetofaunal species across their entire distribution range. Furthermore, including data from both native and introduced ranges is desirable to calibrate the models to capture a wider range of the species potential tolerances, thus avoiding the projection of the climatic envelope to areas outside the calibration range (Randin and others 2006). Additionally, point-locality data extracted from museum specimens might also suffer from sampling biases, with individual points containing a significant degree of error (Graham and others 2008). Biological collection data in general tends to show biases, with a disproportionate amount of data from areas clustered about universities, roads and more accessible localities (Stohlgren and Schnase 2006). This can have serious implications for climate models (Rodda and others 2007). Further bias may result where species are classified separately by some sources and together by others, resulting in discordant distribution sets (for example compare the model results of Ambystoma tigrinum and A. mavortium, which is included as a subspecies within A. tigrinum by many sources).

Another source of error is the mal-characterization of the climatic envelope, due to the inclusion of inappropriate environmental data at the scale of analysis (Guisan and others 2007; Peterson and Nakazawa 2008). For example, for tropical species such as Gekko gecko and Hemidactylus mabouia it may have been more appropriate to include a factor such as the length of the growing season into the matching algorithm, which would reflect the aseasonal climate of these species and avoid predictions into unsuitable areas (such as Scotland, Seattle and Tasmania, which seem unlikely homes for these tropical species). In relation to this, we also need to take into account that the parameterization of the model is scale dependent and the environmental variables included in the analysis will change with the spatial grain (Willis and Whittaker 2002). Variables that explain the distribution of a species at local spatial scales might decrease their predictive power at 
coarser spatial grains (Menke and others 2009). An example of this is the water-snake, Nerodia fasciata. This species is invasive in California, despite this area being outside the main regions predicted as suitable. Rainfall may be irrelevant for such a water-inhabiting species provided its aquatic habitat remains intact. The inclusion of other environmental features, such as the presence/distribution of water bodies, to the matching algorithm could improve predictions for such species. However, at the global scale of this study, such features were precluded. This could have profound repercussions for management if such a species were permitted in trade on the basis of 'no climate match', highlighting the importance of considering each species individually, with due reference to aspects of the biology and ecology of the species.

In relation to the aforementioned errors associated with occurrence and environmental data, predicting suitable climatic conditions for species endemic to small islands (e.g. Eleutherodactylus planirostris) was particularly problematic. These species tend to have only few points in the native range for model input, and in many cases the bounds of the native distribution range did not coincide with the bounds of the species' environmental tolerance. Many of these species thrive on nearby islands or the mainland when translocated (Lever 2003), emphasizing that dispersal rather than environmental barriers limit distribution. These factors lead to narrower predictions of potentially suitable climatic conditions in other parts of the world, perhaps limiting the application of the techniques used here for island species. Similar problems exist for species with a native distributional range highly constrained by biotic interactions, since competitors, predators and parasites might limit the species from occupying the entire tolerance range of the species (Soberón and Peterson 2005). Thus, species could extend their ranges beyond areas which are climatically suitable in the native range, due to "escape from biotic constraints" (Mack and others 2000). For example, only 16 species of parasitic helminthes have been found on cane toads in Australia, despite 59 being recorded in their native range (Torchin and Mitchell 2004), which may contribute to the toad's prolific expansion in the region.

Finally, there are also a series of errors inherently associated with bioclimatic envelope modeling. Different techniques provide different predictions (Elith and others 2006), and there are several limitations associated with the evaluation indices (Manel and others 2001; Lobo and others 2008). Major advances are being made in this field and improved modeling methods will hopefully be available soon to provide user-friendly techniques for managers. We hoped that the "biomes approach" used here would suffice as a simple technique for assessing suitability of areas where data are scarce. This approach had several limitations of which the effect of using small input areas for model calibration was particularly problematic, as this lead to small areas of predicted suitability. Consequently, when adequate data are available for a more in-depth analysis, methods other than the biomes approach should be used. However, in cases where lack of distribution data is severely limiting, existing world biome or vegetation maps may provide a useful first estimate of a species likelihood of survival.

\section{Conclusions}

We have produced maps of worldwide climatic suitability for 67 herpetofaunal species which have immediate applicability for screening. Further, protocols for incorporating climate matching objectively into risk assessment have been detailed. This study has also shed light on data options that are generally available for climate-suitability modeling for herpetofauna. Our results show that the best approach, given the caveats discussed above, depends on the number of species to be assessed and the regions of origin and introduction of these species. NatureServe data yielded the most accurate models for amphibians, while ecoregion data compiled by WWF yielded models which described reptile climatic suitability better than available point-locality GBIF data. Where models are being built for few species, more detailed analyses can be done. In such cases the scale and explanatory variables could be tailored to suit the traits of the species in question, improving model accuracy. Though sparse data makes modeling and model testing difficult, management decisions regarding alien species still need to be taken. There are no quick-fix solutions, and the issues discussed above need to be considered in each evaluation.

Acknowledgments We thank Wilfried Thuiller for advice on modeling, Ladislav Mucina for assistance in identifying biomes in Florida and California, Kirk Klausmeyer for advice on obtaining digital data sets on species distributions, Walter Meshaka for commenting on species invasion success in Florida, and Mark Burgman, Jane Elith and Michael McCarthy for advice on statistical analyses, and four anonymous reviewers for helpful comments. Financial support for this work came from the Australian Centre of Excellence for Risk Analysis (ACERA) (NvW), the DST-NRF Centre of Excellence for Invasion Biology, the Wilhelm Frank Bursary Fund $(\mathrm{NvW})$, Cape Action for People and the Environment (C.A.P.E.), the Beatriu de Pinós postdoctoral grant (2006 BP-A 10124) from the Catalan Agency for Management of University and Research Grants (NRP), and the Hans Sigrist Foundation (DMR).

\section{Appendix}

See Table 3 


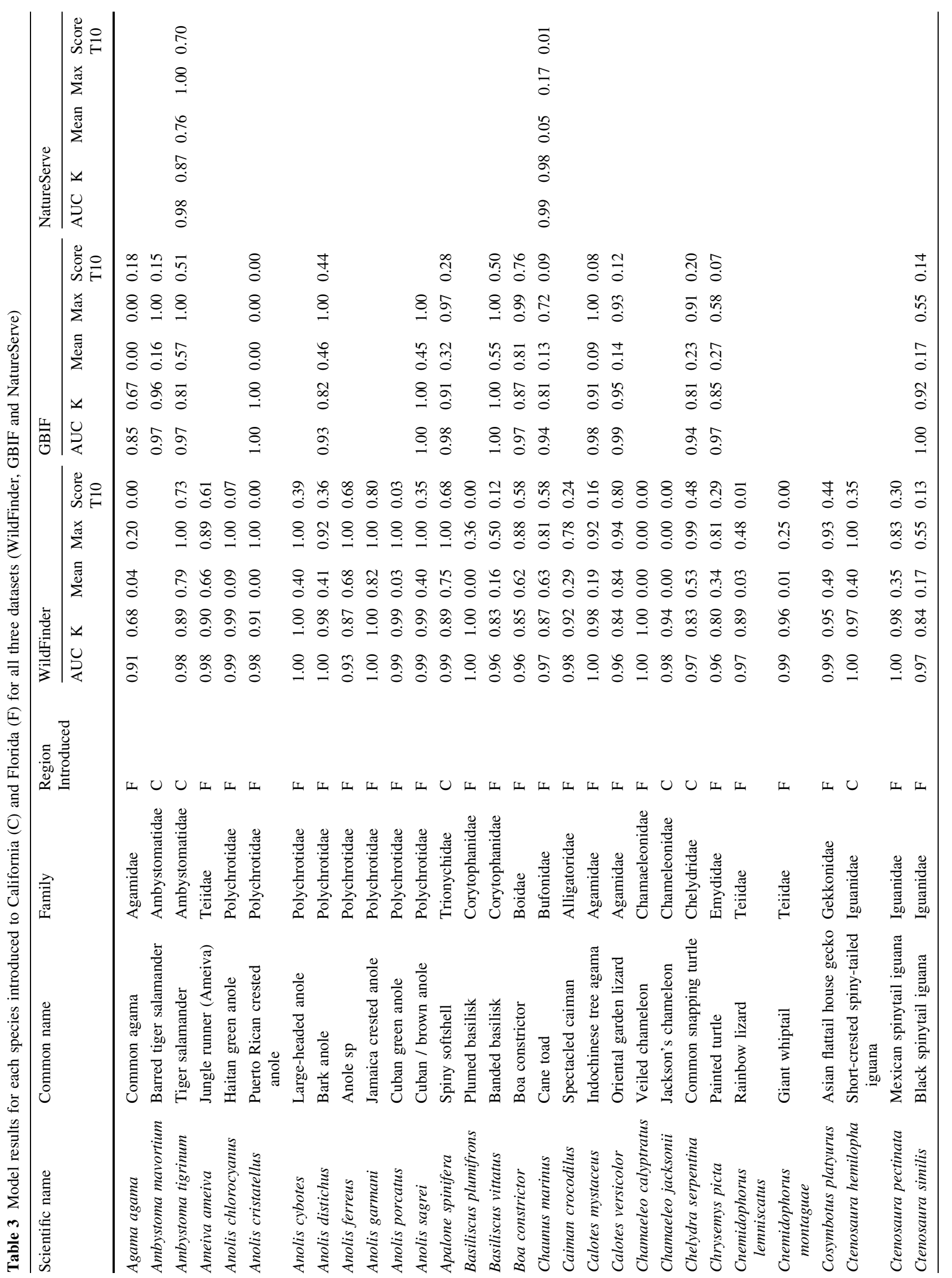




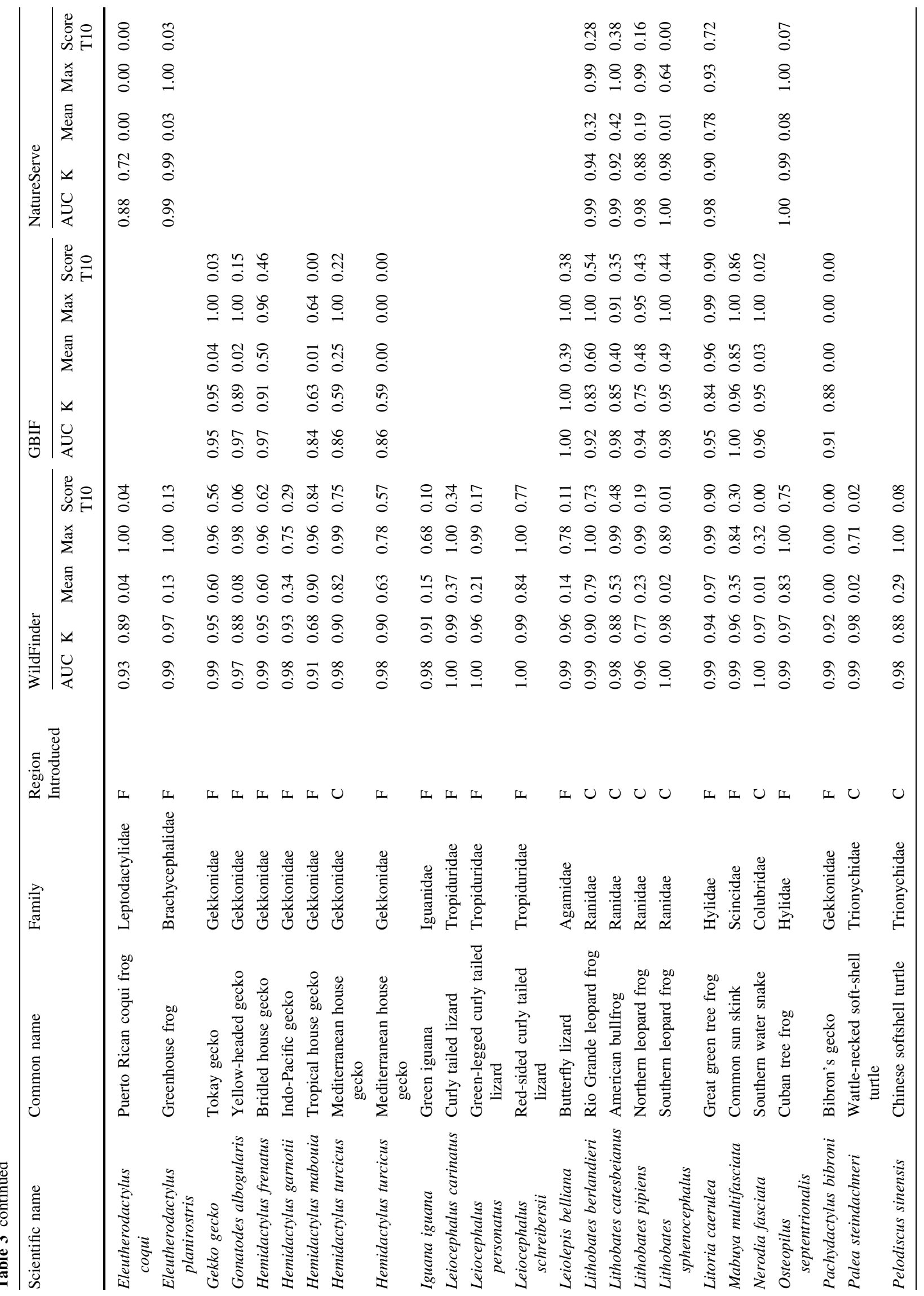




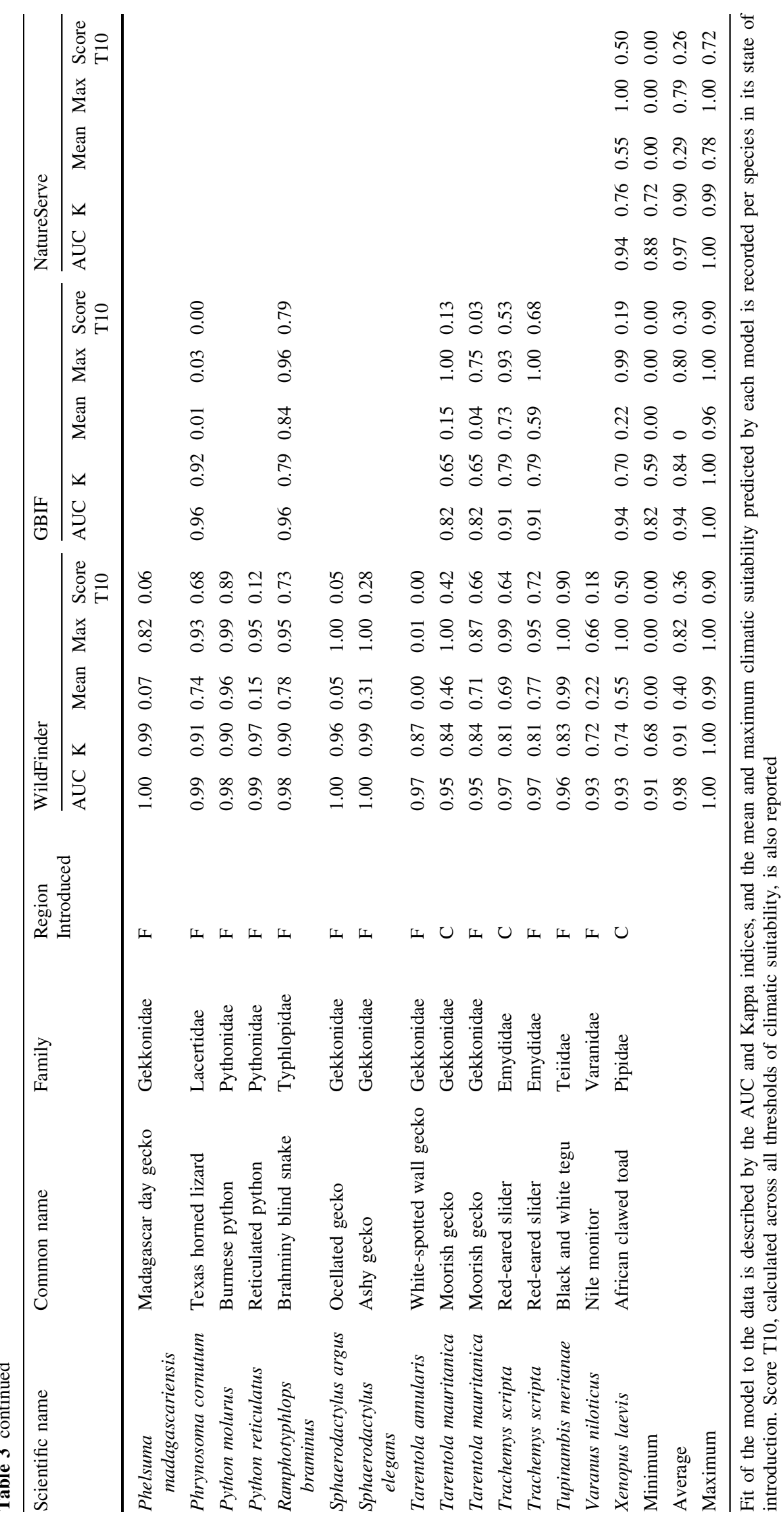




\section{References}

Arntzen JW (2006) From descriptive to predictive distribution models: a working example with Iberian amphibians and reptiles. Frontiers in Zoology 3:8

Blaustein AR, Kiesecker JM (2002) Complexity in conservation: lessons from the global decline of amphibian populations. Ecology Letters 5:597-608

Bomford M, Kraus F, Braysher M, Walter L, Brown L (2005) Risk assessment model for the import and keeping of exotic reptiles and amphibians. Australian Government Bureau of Rural Sciences, Canberra, $107 \mathrm{pp}$

Bomford M, Kraus F, Barry SC, Lawrence E (2009) Predicting establishment success for alien reptiles and amphibians: a role for climate matching. Biological Invasions 11:713-724

Cohen J (1960) A coefficient of agreement for nominal scales. Educational Psychology Measurement 20:37-46

Collins JT (1994-2008) The Centre for North American Herpetology. http://www.cnah.org/ex_nameslist.asp. Accessed 5 February 2008

Costa GC, Wolfe C, Shepard DB, Caldwell JP, Vitt LJ (2008) Detecting the influence of climatic variables on species distributions: a test using GIS niche-based models along a steep longitudinal environmental gradient. Journal of Biogeography 35:637-646

Daehler CC, Carino DA (2000) Predicting invasive plants: prospects for a general screening system based on current regional models. Biological Invasions 2:93-102

Elith J, Graham CH, Anderson RP, Dudik M, Ferrier S, Guisan A, Hijmans RJ, Huettmann F, Leathwick JR, Lehmann A, Li J, Lohmann LG, Loiselle BA, Manion G, Moritz C, Nakamura M, Nakazawa Y, Overton JM, Peterson AT, Phillips SJ, Richardson K, Scachetti-Pereira R, Schapire RE, Soberon J, Williams S, Wisz MS, Zimmermann NE (2006) Novel methods improve prediction of species' distributions from occurrence data. Ecography 29:129-151

Ferrier S, Watson G, Pearce J, Drielsma M (2002) Extended statistical approaches to modelling spatial pattern in biodiversity in northeast New South Wales. I. Species-level modelling. Biodiversity and Conservation 11:2275-2307

Ficetola GF, Thuiller W, Miaud C (2007) Prediction and validation of the potential global distribution of a problematic alien invasive species-the American bullfrog. Diversity and Distributions 13:476-485

Ficetola GF, Thuiller W, Padoa-Schioppa E (2009) From introduction to the establishment of alien species: bioclimatic differences between presence and reproduction localities in the slider turtle. Diversity and Distributions 15:108-116

Fielding AH, Bell JF (1997) A review of methods for the assessment of prediction errors in conservation presence/absence models. Environmental Conservation 24:38-49

Fisher RN, Case TJ (2003) A field guide to the reptiles and amphibians of coastal southern California. http://www.werc. usgs.gov/fieldguide/. Accessed January 2008

Florida Fish and Wildlife Conservation Commission (1999-2008) Welcome to nonnative species information. http://myfwc.com/ nonnatives/. Accessed April 2008

Franklin J, Wejnert KE, Hathaway SA, Rochester CJ, Fisher RN (2009) Effect of species rarity on the accuracy of species distribution models for reptiles and amphibians in southern California. Diversity and Distributions 15:167-177

Frost DR, Grant T, Faivovich J, Bain RH, Haas A, Haddad CFB, De Sa RO, Channing A, Wilkinson M, Donnellan SC, Raxworthy CJ, Campbell JA, Blotto BL, Moler P, Drewes RC, Nussbaum RA, Lynch JD, Green DM, Wheeler WC (2006) The amphibian tree of life. Bulletin of the American Museum of Natural History 297:370 pp

GBIF (Global Biodiversity Information Facility) (2008) GBIF data portal. www.gbif.net. Accessed January 2008

Giovanelli JGR, Haddad CFB, Alexandrino J (2007) Predicting the potential distribution of the alien invasive American bullfrog (Lithobates catesbeianus) in Brazil. Biological Invasions 10:585-590

Gordon DR, Onderdonk DA, Fox AM, Stocker RK (2008) Consistent accuracy of the Australian weed risk assessment system across varied geographies. Diversity and Distributions 14:234-242

Graham CH, Elith J, Hijmans RJ, Guisan A, Peterson AT, Loiselle BA, The NCEAS Predicting Species Distributions Working Group (2008) The influence of spatial errors in species occurrence data used in distribution models. Journal of Applied Ecology 45:239-247

Guisan A, Hofer U (2003) Predicting reptile distributions at the mesoscale: relation to climate and topography. Journal of Biogeography 30:1233-1243

Guisan A, Zimmermann NE (2000) Predictive habitat distribution models in ecology. Ecological Modelling 135:147-186

Guisan A, Graham CH, Elith J, Huettmann F, The NCEAS Species Distribution Modelling Group (2007) Sensitivity of predictive species distribution models to change in grain size. Diversity and Distributions 13:332-340

Hanley JA, McNeil BJ (1982) The meaning and use of the area under a receiver operating characteristic (ROC) curve. Radiology 143:29-36

Heikkinen RK, Luoto M, Araújo MB, Virkkala R, Thuiller W, Sykes MT (2006) Methods and uncertainties in bioclimatic envelope modelling under climate change. Progress in Physical Geography 30:751-777

Hijmans RJ, Cameron SE, Parra JL, Jones PG, Jarvis A (2005) Very high resolution interpolated climate surfaces for global land areas. International Journal of Climatology 25:1965-1978

IUCN, Conservation International, and NatureServe (2006) Global amphibian assessment. www.globalamphibians.org, version 1.1. http://www.natureserve.org/getData/amphibianMaps.jsp. Accessed 8 April 2008

Kaiser J (1999) Stemming the tide of invading species. Science 285:1836-1841

Keller RP, Lodge DM, Finnoff DC (2007) Risk assessment for invasive species produces net bioeconomic benefits. Proceedings of the National Academy of Sciences of the United States of America 104:203-207

King KW (1996-2006) Florida Museum of Natural History's checklist of Florida amphibians and reptiles. http://www.flmnh. ufl.edu/natsci/herpetology/fl-guide/flaherps.htm\#TOP. Accessed April 2008

Kolar CS, Lodge DM (2001) Progress in invasion biology: predicting invaders. Trends in Ecology \& Evolution 16:199-204

Kolar CS, Lodge DM (2002) Ecological predictions and risk assessment for alien fishes in North America. Science 298: $1233-1236$

Kupferberg SJ (1997) Bullfrog (Rana catesbeiana) invasion of a California river: the role of larval competition. Ecology 78:1736-1751

Lever C (2003) Naturalized reptiles and amphibians of the world. Oxford University Press, New York, 318 pp

Lobo JM, Jimenez-Valverde A, Real R (2008) AUC: a misleading measure of the performance of predictive distribution models. Global Ecology and Biogeography 17:145-151

Mack RN, Simberloff D, Lonsdale WM, Evans H, Clout M, Bazzaz FA (2000) Biotic invasions: causes, epidemiology, global 
consequences, and control. Ecological Applications 10:689710

Manel S, Williams HC, Ormerod SJ (2001) Evaluating presenceabsence models in ecology: the need to account for prevalence. Journal of Applied Ecology 38:921-931

Menke SB, Holway DA, Fisher RN, Jetz W (2009) Characterizing and predicting species distributions across environments and scales: Argentine ant occurrences in the eye of the beholder. Global Ecology and Biogeography 18:50-63

Meshaka WE Jr, Butterfield BP, Hauge JB (2004) The exotic amphibians and reptiles of Florida. Krieger Publishing Company, Malabar, $155 \mathrm{pp}$

Meshaka WE, Smith HT, Severson R, Severson MA (2005) Spatial picture of a gecko assemblage in flux. Biological Sciences 68:53-55

Meshaka WE, Cress HL, Kingsland KL, Smith HT, Fitchett SA, Moore JA, Cowan EM (2006) Hemidactylus (House Gecko) assemblage dynamics on South Florida buildings. Journal of Kansas Herpetology 17:7-8

Nafis G (2000-2008) California reptiles and amphibians. http://www. californiaherps.com/. Accessed April 2008

New M, Lister D, Hulme M, Makin I (2002) A high-resolution data set of surface climate over global land areas. Climate Research 21:1-25

Peterson AT, Nakazawa Y (2008) Environmental data sets matter in ecological niche modelling: an example with Solenopsis invicta and Solenopsis richteri. Global Ecology and Biogeography 17:135-144

Pheloung PC, Williams PA, Halloy SR (1999) A weed risk assessment model for use as a biosecurity tool evaluating plant introductions. Journal of Environmental Management 57: 239-251

Pitt WC, Vice DS, Pitzler ME (2005) Challenges of invasive reptiles and amphibians. In: Proceedings of the 11th wildlife damage management conference, pp 112-119

Pyron RA, Burbrink FT, Guiher TJ (2008) Claims of potential expansion throughout the U.S. by invasive python species are contradicted by ecological niche models. PLoS ONE 3:e2931

Randin CF, Dirnbock T, Dullinger S, Zimmermann NE, Zappa M, Guisan A (2006) Are niche-based species distribution models transferable in space? Journal of Biogeography 33:1689-1703

R Development Core Team (2007) R: a language and environment for statistical computing. R Foundation for Statistical Computing, Vienna, Austria. ISBN 3-900051-07-0. http://www.R-project.org

Reed RN (2005) An ecological risk assessment of nonnative boas and pythons as potentially invasive species in the United States. Risk Analysis 25:753-766

Richardson DM, Thuiller W (2007) Home away from homeobjective mapping of high-risk source areas for plant introductions. Diversity and Distributions 13:299-312

Rodda GH, Reed RN, Jarnevich CS (2007) Climate matching as a tool for predicting potential North American spread of brown treesnakes. Managing vertebrate invasive species: USDA national wildlife research center symposia. University of Nebraska, Lincoln

Rodda GH, Jarnevich CS, Reed RN (2009) What parts of the US mainland are climatically suitable for invasive alien pythons spreading from Everglades National Park? Biological Invasions $11: 241-252$

Soares C, Brito JC (2007) Environmental correlates for species richness among amphibians and reptiles in a climate transition area. Biodiversity and Conservation 16:1087-1102

Soberón J, Peterson AT (2005) Interpretation of models of fundamental ecological niches and species' distributional areas. Biodiversity Informatics 2:1-10

Stohlgren TJ, Schnase JL (2006) Risk analysis for biological hazards: what do we need to know about invasive species? Risk Analysis 26:163-173

Sutton T, de Giovanni R, de Siqueira MF (2007) Introducing openModeller: a fundamental niche modelling framework. OSGeo Journal 1. ISSN:1994-1897

Teixeira J, Ferrand N, Arntzen JW (2001) Biogeography of the golden-striped salamander Chioglossa lusitanica: a field survey and spatial modelling approach. Ecography 24:618-624

Thuiller W (2003) BIOMOD_optimizing predictions of species distributions and projecting potential future shifts under global change. Global Change Biology 9:1353-1362

Torchin ME, Mitchell CE (2004) Parasites, pathogens, and invasions by plants and animals. Frontiers in Ecology and the Environment 2:183-190

USEPA (United States Environmental Protection Agency) (2007) Ecoregions of North America. http://www.epa.gov/wed/pages/ ecoregions/na_eco.htm. Accessed February 2007

van Wilgen NJ, Richardson DM, Baard EHW (2008) Alien reptiles and amphibians in South Africa: towards a pragmatic management strategy. South African Journal of Science 104:13-20

Veltman CJ, Nee S, Crawley MJ (1996) Correlates of introduction success in exotic New Zealand birds. American Naturalist 147:542-557

Williamson M (1999) Invasions. Ecography 22:5-12

Willis KJ, Whittaker RJ (2002) Ecology—species diversity—scale matters. Science 295:1245-1248

Wilson JRU, Richardson DM, Rouget M, Procheş Ş, Amis MA, Henderson L, Thuiller W (2007) Residence time and potential range: crucial considerations in modelling plant invasions. Diversity and Distributions 13:11-22

Woolf A, Nielsen CK, Weber T, Gibbs-Kieninger TJ (2002) Statewide modeling of bobcat, Lynx rufus, habitat in Illinois, USA. Biological Conservation 104:191-198

WWF (World Wildlife Fund) (2006) WildFinder: online database of species distributions, ver. Jan-06. http://www.worldwildlife.org/ wildfinder/searchBySpecies.cfm. Accessed January 2008 